\title{
THE APPLICATION OF ECOLOGICAL THINKING TO BETTER UNDERSTAND THE NEEDS OF COMMUNITIES OF OLDER PEOPLE
}

\begin{abstract}
Objectives: This research applied ecological thinking to develop a more integrated or ecological understanding of the needs and aspirations of communities of older people.

Method: A three stage methodology was utilised. Stage one entailed the thematic analysis of resident satisfaction surveys collected from 1000 residents of aged living and care facilities to identify issues impacting upon their lives. In stage two these findings were critiqued through a key stakeholder forum. In stage three findings were authenticated through resident interviews and workshops.

Results: The findings suggest that an ecological framework for the wellbeing of older people living in residential communities can be conceptualised as the four domains of the physical environment, social environment, governance and active living.

Conclusions: This framework for the ecology of resident wellbeing developed through the research informs an ecological approach to service providers' planning to promote the health and wellbeing of residents of communities of older people.
\end{abstract}

Keywords: ecology of resident wellbeing, aged service and care, settings, quality of life, health promotion, determinants of health.

\section{Key Points}

- Researchers collected and analysed data which enabled a better understanding of the resident's perspective of wellbeing in residential communities.

- The analysis produced a model of the ecology of resident wellbeing which will provide a framework for improved planning and management of complex interventions with older people.

- Designing a salutogenic or health enabling ecosystem for communities of older people will enable older people to live more active and rewarding lives.

Acknowledgements: Project funded by a Griffith University Industry Collaborative Scheme grant, RSL Care and Wesley Mission Brisbane. 


\section{Introduction}

The economic and social implications of our ageing population make it an imperative for the aged living and care sector to develop frameworks that facilitate healthy ageing by promoting a more productive, engaged and active older population $[1,2,3]$. In order to facilitate and measure the inevitably complex and rapid changes within this sector, there is a need to shift the emphasis from care that helps people live with chronic disease to care that enables healthy life choices [4]. Amongst people over the age of $65,60 \%$ suffer from some sort of chronic health condition that impacts their daily activities and wellbeing [4]. As our population ages, there will be a commensurate need to decrease the extent of chronic illness experienced by people aged over 65 years.

In recent years there has been a shift within the discipline of health promotion to a settings based approach to health. The settings approach to health promotion has worked to situate human health within a theoretical framework of ecological thinking. This framework is based on the understanding that the health of individuals within a population or community is inextricably linked with the health of the ecosystem [5]. This way of thinking is underpinned by the view that health and inversely disease cannot be understood by solely studying individuals but must also incorporate the systems that people are situated within $[6,7]$. The settings approach advocates change within the whole system or organisation, recognising that many of the determinants of health are social or environmental in nature and not within the direct control of the individual [8].

Within environmental gerontology [9], researchers have studied topics such as the social setting in which the older person engages with the community $[10,11]$, the physical setting as it relates to building design [12] and the organisational environment and how services for older people are managed. Work in environmental gerontology is consistent with the settings approach to health promotion and a synthesis of the two schools of thought could inform the development of a more inclusive or ecological approach to wellbeing for older people living in residential communities. 
The realignment of thinking must commence with an understanding of the issues and concerns impacting wellbeing and care as expressed by the population of interest: namely residents of aged living and care facilities $[13,14,15]$. This research sought to better understand the ecology of communities of older people and thereby develop a more integrated or ecological explanation of the needs and aspirations of these communities. Understanding resident aspirations would structure our understanding of an ecological framework for resident wellbeing.

\section{Design and Methods}

The study was qualitative in nature and adopted a three stage process.

Stage One: Identify needs

A thematic analysis was conducted on data obtained from annual satisfaction surveys administered by research partners RSL Care and Wesley Mission Brisbane during 2005 and 2006. These surveys are conducted annually by our partners with residents in each of their facilities. Partners provide different levels of care from extended care circumstances that provide ongoing care for those with restricted functionality, hostels where people are semiindependent with some support services such as meals and independent living units. Surveys were collected from over 1000 residents, although specific demographic information is not collected within these surveys, all respondents were aged over 65 years, the large majority aged 80 years and over with the majority being female consistent with the aged population generally.

The surveys comprised a series of closed questions seeking information about satisfaction with services such as food, staff and facilities. One open ended question invited residents to indicate issues that are impacting on their wellbeing. Data from this question provided a unique qualitative data set of solicited views and recommendations from residents. The data was extracted from the surveys by partner staff and provided to researchers as de-identified comments. The researchers then undertook preliminary coding to cluster common issues 
and topics. These clusters were reviewed and refined collaboratively across several meetings by the researchers until agreement was reached on groupings, representative thematic labels could be assigned to each cluster and the emergent ecological framework drafted for discussion [16].

Phase Two: Corroborate needs

During this phase a one day stakeholder consultation forum was conducted to corroborate the findings of Phase 1. Informed by a stakeholder analysis, 30 participants were invited by direct invitation to key organisations associated with aged care and living. Attendees included representatives from advocacy groups (e.g. Council on the Ageing, Older People Speak Out and Australian Association of Gerontology), leaders from the aged service industry (e.g. senior staff from aged living providers including Wesley Mission Brisbane and RSL Care), academics (e.g. Health Promotion and Aged Care/Living) and policy makers (e.g. Department of Health and Ageing, Aged Care Queensland) The workshop provided a forum to debate the issues identified as impacting on the wellbeing of older people and the role that an ecological approach could play in improving the situation. The framework developed in phase one was presented to the group and discussed in detail. This discussion was documented through hand written minutes which directly informed refinements of the framework.

Phase Three: Confirm needs

In this phase of the research the framework developed across phases 1 and 2 was taken back to residents of aged living and care facilities for member validation. The purpose was to provide residents with the opportunity to critique the framework including the adequacy of the framework in representing the needs of older residents of aged living and care facilities. The researchers conducted 2 workshops each attended by more than 50 residents, purposively chosen for their active role in facility life and governance within six independent living facilities. The workshop incorporated facilitated small group discussions of the framework provided to residents prior to the workshop. Hand written notes were taken on the 
discussion and key points raised within each small group. In addition, 10 semi-structured interviews were conducted with extended care and hostel residents nominated by carers.

The three phase process followed by the researchers enabled progression from preliminary identification and analysis of primary data, through to stakeholder review and refinement of this analysis to resident validation of the explanation developed. Phase 2 and 3 of the research invited critical dialogue around the framework and its components. The outcome of these processes provided a rigorous approach to validating the trustworthiness of the framework presented below.

Ethics approval for the study was obtained through Griffith University Human Research Ethics Committee (Protocol no. PBH/02/07/HREC).

\section{Results}

In the table below a summary of the thematic analysis is presented. The 3 Columns present 3 components of the analytical process. In Column 3 primary data are presented in the form of selected examples of resident comments. Column 2 shows the first level of analysis where comments are grouped into personal, communal and societal levels. Column 1 shows that further analysis of comments within levels enabled the conceptualisation of results into the four domains of physical environment, social environment, governance and active living.

Table 1: Thematic Analysis of Resident Comments

\begin{tabular}{|l|l|l|}
\hline Domain & Level & Resident “voices" - examples of resident comments \\
\hline $\begin{array}{l}\text { Physical } \\
\text { environment }\end{array}$ & Personal & $\begin{array}{l}\text { - The toilet/bathroom is a disaster area. } \\
\text { - Untidy gardens also don't reflect well on the general appearance of which is a pity. }\end{array}$ \\
\cline { 2 - 3 } & Communal & $\begin{array}{l}\text { - I think it would be good for an entrance light to be installed at the entrance. } \\
\text { - Lawns left too long between mowings, whipper snipper trimming not done } \\
\text { properly. }\end{array}$ \\
\cline { 2 - 3 } $\begin{array}{l}\text { Social } \\
\text { environment }\end{array}$ & Societal & $\begin{array}{l}\text { - Village well positioned having access to shops, businesses, doctors etc. } \\
\text { - One thing we do miss is the opportunity to interact with wildlife (birds etc) }\end{array}$ \\
\cline { 2 - 3 } & Personal & $\begin{array}{l}\text { - We have a very comfortable unit and feel very safe at all times. } \\
\text { - I love the neighbours, the staff are great. Love them all, hope I am lucky enough to } \\
\text { be here for another 7 years. }\end{array}$ \\
\cline { 2 - 3 } & Communal & $\begin{array}{l}\text { - Closed circuit TV monitoring needs to be more widely used for the security of } \\
\text { residents. } \\
\text { - We love the concept and all the residents that have bonded together. }\end{array}$ \\
\cline { 2 - 3 } & Societal & $\begin{array}{l}\text { - Very disappointed in reduction in number of outings from fortnightly to monthly. } \\
\text { - I am quite satisfied with most everything, just lonely with no family here in }\end{array}$ \\
\hline
\end{tabular}




\begin{tabular}{|c|c|c|}
\hline & & Australia. \\
\hline \multirow[t]{3}{*}{ Governance } & Personal & $\begin{array}{l}\text { - I think we need some up-to-date information on current unit values \& clarification } \\
\text { of sale obligations. }\end{array}$ \\
\hline & Communal & $\begin{array}{l}\text { - The residents committee was a great idea } \\
\text { - Management is very approachable in any circumstances \& very obliging, creating a } \\
\text { harmonious environment }\end{array}$ \\
\hline & Societal & $\begin{array}{l}\text { - I was disappointed to have no voting facility at the complex for the recent state } \\
\text { elections, contrary to what has been advised prior to election day. }\end{array}$ \\
\hline \multirow[t]{3}{*}{ Active Living } & Personal & - I long to be dressed absolutely no later than 10am. \\
\hline & Communal & $\begin{array}{l}\text { - Several residents have midday meals provided by .... but as the years go by the } \\
\text { residents are finding it difficult to walk to the kitchen to obtain the meals. } \\
\text { - The care part of .... is missing. If it was not for the care of people like ...... many } \\
\text { residents would be in distress. }\end{array}$ \\
\hline & Societal & $\begin{array}{l}\text { - We were disappointed with the reality of what is emergency care. We expected } \\
\text { more than first aid only. }\end{array}$ \\
\hline
\end{tabular}

\section{Discussion}

As an outcome of the thematic analysis an explanatory framework for the ecology of resident wellbeing was developed. Figure 1 presents this framework. The framework incorporates all four domains across three levels and provides a framework to guide service provision. Organisations would need to consider each domain in planning, implementing and evaluating activities in order to ensure satisfactory outcomes for services in enabling clients to meet their needs. While these domains have been separated for clarity, consistent with an ecological approach, it should be understood that the domains are interconnected and that a failure within any of the domains would lead to a cascade of shortcomings across the domains [17]. For example, a limitation to the physical environment described by residents such as poor lighting could reduce residents' access to essential areas of the facility such as common meeting rooms thus impacting on both active living and social engagement with fellow residents.

Figure 1: Explanatory framework of the Ecology of Resident Wellbeing 


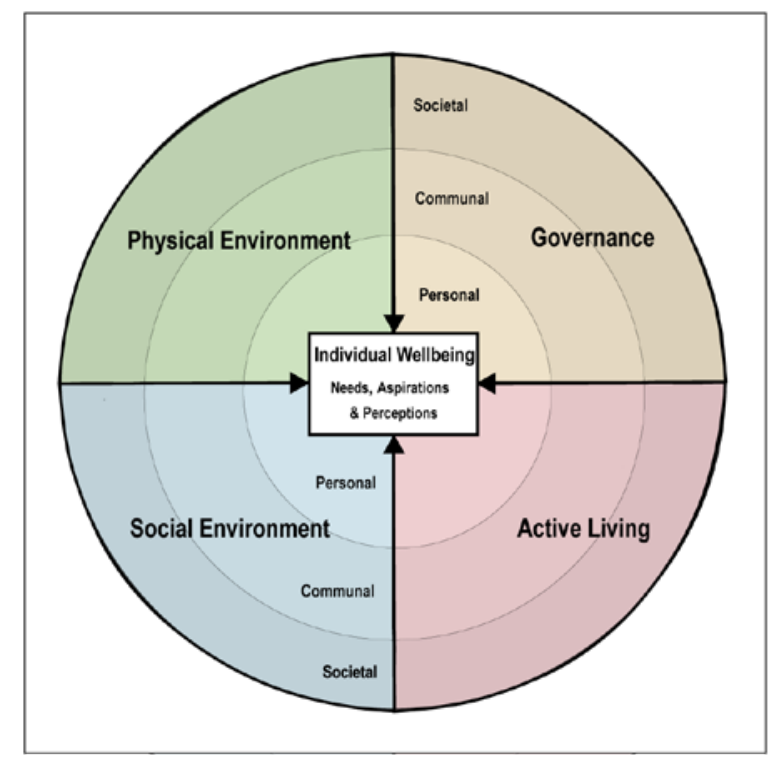

The thematic analysis revealed that at the centre of the framework is the individual. Each individual resident is a unique human being whose needs will depend greatly on their current circumstances and as the circumstances change inevitably the person's needs and aspirations will change. These findings are consistent with the theory of Gerotranscendence [18] as they provide a framework for understanding, sustaining and potentially increasing life satisfaction as the person ages. A resident's individual wellbeing is inextricably linked with the four domains identified in the framework and described in the following paragraphs.

Physical environment: consists of both built and natural environments. Residents identified such issues as gardens, recreational facilities, shopping centres, and bathroom and kitchen layout and access. With regard to the built environment, the importance of residence design to enhance functional ability is well described in the literature $[12,19]$. Buildings can have characteristics that do not support or even inhibit an individual's capacity to perform certain functions. Something as simple as a tight tap handle or loose pavers in a footpath can become a significant hurdle for an older person. With regard to the natural environment, the data showed that residents want to maintain contact with nature in their personal gardens or in communal green space. Our findings resonate with Thomas [20] who has advocated the benefit of engagement in activities in and around nature for resident wellbeing. 
Social environment: includes relationships and the sense of belonging or connectedness, as well as services and facilities that enable interaction with family, friends and community. The significance of social capital including social relations to the health and lives of older people has been discussed by Cannuscio and colleagues [21]. Residents showed particular concern when a service provider unintentionally isolated a resident from friends and family, for example through poor signage creating confusion for visitors or overgrown gardens which made pedestrian access more difficult. Conversely, activities and facilities that promoted a continuation of relationships were highly valued such as efforts to build a pergola as a private meeting space for residents and their family. The data indicated that social relationships are extremely important for residents; people need to connect with other people whether that is staff, family, friends or volunteers.

Governance: refers to the power one has to be able to determine aspects of life and the importance of personal involvement in communal decision-making. Wilson and Kirby [22] report that up to $65 \%$ of communities of older people have active residential committees. Resident comments around inability to vote in National elections and interest in facility annual plans and budgets demonstrates that residents are keen to remain active at all levels of governance. Service providers need to be aware that residents value their role in decision making processes. This was expressed in the data through matters as simple as choice of clothing to matters as important as the direction and planning of the communities they are part of to participating in national elections.

Active Living: A person's functional ability allows the person to carry out activities of daily living $[18,23]$, however, disability which limits a person's function does not necessarily lead to a reduction in that person's quality of life. The individual's reaction to this circumstance will depend on access to and type of services which enable daily activities. The data indicated that no matter what their age, people need or want to work, learn and play in order to gain a sense of self efficacy from successful completion of activities [24]. 
Under this domain, residents highlighted care provided by society such as general practitioners, volunteers, community nurses, hospitals, and the availability of services within the communal setting such as meals, mobility support and provision of emergency services. Residents do not see a lack of function as leading to an inevitable loss of quality of life. Katz [23] was a pioneer in measuring functional ability of older people which is described in the literature as "activities of daily living". A different label is used in this framework as the authors wish to differentiate the concept from the idea that activities of daily living are a measure of functional health. This model places the emphasis on how services and care enable the resident's functional ability; as such it may be seen as a more positive approach when compared to measures of functional deficit.

In organising the data relating to the issues identified, it became apparent that across all of the four domains, issues could be clustered within three levels. These levels were:

- Personal: The personal level encompasses those issues or components immediately related to the self such as the domestic environment, close family, spiritual beliefs, and the ability to care for oneself;

- Communal: The communal level refers to issues within the shared space of the aged care facility or retirement village; and

- Societal: The societal level refers to the broader community beyond the bounds of the facility.

While the analysis has shown that the three levels are consistently represented across the four domains, they do not always have the same significance in an individual's life. Their significance can change over time or vary considerably along the continuum of care. This change is particularly evident in the levels of resident engagement at the societal level. For example, we found that individuals with a greater level of independence were focused on all levels of social engagement while people with higher levels of dependence were less interested in the world external to their community in all aspects except family. Therefore, it 
would be anticipated that interest in or relevance of each of the four domains is not static and would also vary as a function of an individual's progression along the continuum of care. For example, with respect to contact with the natural environment, we found that as a resident's autonomy declined interest shifted from outside gardens to plants in their rooms. Examination of how this manifests would be of considerable research, policy and service delivery interest and will represent an important step in the framework's development and medium term validation.

\section{Conclusion}

This framework provides researchers primary evidence for the construction of new and innovative instruments which can be attributed to the expressed needs of residents. The analysis of needs and aspirations of residents in communities of older people enabled the researchers in collaboration with residents and key stakeholders to define the ecology of resident wellbeing. Providers of aged living and care commit a great deal of time and resources to meeting government accreditation standards for quality of care. This activity does not comprehensively provide managers with the platform to guide the direction and evaluation of services from a resident perspective. What the ecology of resident wellbeing provides is a basis for health service planners to better understand and act upon the issues and broader domains that are important to residents within a holistic framework. The limitations of the research is that rigorous design of the model is only a first step of operationalising sustainable improvement in provision of services to aged people. The next research steps require the piloting of an ecological approach at the site level coupled with testing of the framework.

This paper has provided evidence to support the alignment of the settings based approach to health promotion with environmental gerontology. The application of an ecological approach to the analysis of self identified needs of older people has enabled the researchers to construct a framework to underpin salutogenic or health enabling service provision in communities of older people [25]. The application of the framework for the ecology of 
resident wellbeing would inform the development of multi-level and multi-strategy interventions to promote active and productive life in communities of older people.

\section{References}

1 World Health Organization. Resolutions and Decisions: Strengthening active and healthy ageing. Geneva: World Health Organization, 2005.

2 World Health Organization. Active Ageing: A Policy Framework. Geneva: World Health Organization, 2002.

3 United Nations. International Plan of Action on Ageing. United Nations: Division for Social Policy and Development, 2003.

4 Sidell M. Older People's Health: Applying Antonovsky's Salutogenic Paradigm. In: Douglas J, Earle S, Handsley S et al. A Reader in Promoting Public Health: Challenge and Controversy. London: SAGE Publications, 2007; 33-39.

5 Begon M, Townsend C, Harper L. Ecology: From individuals to ecosystems. (4th ed.). Blackwell; 2006.

6 Baum F. The New Public Health. South Melbourne: Oxford University Press, 2002.

7 Rapport D, Costanza R, Epstein P. Ecosystem Health. Malden Massachusetts: Blackwell Science, 1998.

8 Green L, Poland B, Rootman I. Settings Approach to health promotion. In: Poland B, Green L, Rootman I, eds. Settings for health promotion: linking theory and practice. London: Sage Publications, 2000; 1-36.

9 Wahl H-W, Weisman G. Environmental Gerontology at the Beginning of the New Millennium: Reflections on Its Historical, Empirical and Theoretical Development. The Gerontologist 2003; 43(5): 616-627.

10 Lawton M. Quality of Life in Chronic Illness. Gerontology 1999; 45(4):181-183. 
11 Lawton M. The Elderly in Context: Perspectives from Environmental Psychology and Gerontology. Environment and Behaviour 1985; 17(501)

$12 \mathrm{Kendig} \mathrm{H}$. Directions in environmental gerontology: A multidisciplinary field. The Gerontologist 2003; 43(5): 611-615.

13 Nolan M, Davies S, Grant G. Working with older people and their families. Philadelphia Open University Press, 2001.

14 Wilhelmson K, Andersson C, Waern M, Allebeck P. Elderly people's perspectives on quality of life. Ageing and Society 2005: 25: 585-600.

15 Russell C, Oxley H. Health and ageing in Australia: is there culture after sixty? Journal of Cross-Cultural Gerontology 1990; 5: 35-50.

16 Attride-Stirling J. Thematic Networks: An analytic tool for qualitative research. Qualitative Research 2001;1(3): 355-405.

17 Harris N, Grootjans J, Wenham K. Ecological Aging: The Settings Approach in Aged Living and Care Accommodation. EcoHealth 2008; 5: 196-204.

18 Tornstam L. Gerotranscendence: a developmental theory of positive aging. New York: Springer Publishing Company; 2005.

19 Wahl H-W. The Person Environment Perspective in Ageing research. In: Wahl H-W, Brenner $\mathrm{H}$, Mollenkopf $\mathrm{H}$ et al. eds. The Many Faces of Health, Competence and Wellbeing in Old Age. Dordrecht: Springer, 2006; 3-7.

20 Thomas W. Life Worth Living: How Someone You Love Can Still Enjoy Life in a Nursing Home: The Eden Alternative in Action. Acton, MA: VanderWyk \& Burnham,1996.

21 Cannuscio C, Block J, Kawachi I. Social capital and successful aging: the role of senior housing. Annals of Internal Medicine 2003; 139(5): 395-399.

22 Wilson L, Kirby N. How resident committees function in low-level residential aged care facilities. Australasian Journal on Ageing 2005; 24(4): 207-212.

23 Katz S. Assessing self-maintenance: activities of daily living, mobility and instrumental activities of daily living. Journal American Geriatric Society 1983; 31(12): 721-727. 
24 Bandura A. Human Agency in Social Cognitive Theory. American Psychologist 1989; 44(9): 1175-1184.

25 Antonovsky A. Unravelling the Mystery of Health How People Manage Stress and Stay Well. San Francisco: Jossey-Bass Publishers, 1987. 